\title{
Clipping of previously coiled cerebral aneurysms: efficacy, safety, and predictors in a cohort of 111 patients
}

\author{
Badih Daou, MD, ${ }^{1}$ Nohra Chalouhi, MD, ${ }^{1}$ Robert M. Starke, MD, ${ }^{2}$ Guilherme Barros, MS, ${ }^{1}$ \\ Lina Ya'qoub, MD, ${ }^{1}$ John Do, MD, ${ }^{1}$ Stavropoula Tjoumakaris, MD, ${ }^{1}$ Robert H. Rosenwasser, MD, ${ }^{1}$ \\ and Pascal Jabbour, MD'
}

Departments of Neurosurgery, ${ }^{1}$ Thomas Jefferson University and Jefferson Hospital for Neuroscience, Philadelphia, Pennsylvania; and ${ }^{2}$ University of Virginia, Charlottesville, Virginia

OBJECTIVE With the increasing number of aneurysms treated with endovascular coiling, more recurrences are being encountered. The aim of this study was to evaluate the efficacy and safety of microsurgical clipping in the treatment of recurrent, previously coiled cerebral aneurysms and to identify risk factors that can affect the outcomes of this procedure.

METHODS One hundred eleven patients with recurrent aneurysms whose lesions were managed by surgical clipping between January 2002 and October 2014 were identified. The rates of aneurysm occlusion, retreatment, complications, and good clinical outcome were retrospectively determined. Univariate and multivariate logistic regressions were performed to identify factors associated with these outcomes.

RESULTS The mean patient age was 50.5 years, the mean aneurysm size was $7 \mathrm{~mm}$, and $97.3 \%$ of aneurysms were located in the anterior circulation. The mean follow-up was 22 months. Complete aneurysm occlusion, as assessed by intraoperative angiography, was achieved in 97.3\% of aneurysms (108 of 111 patients). Among patients, 1.8\% (2 of 111 patients) had a recurrence after clipping. Retreatment was required in $4.5 \%$ of patients (5 of 111) after clipping. Major complications were observed in $8 \%$ of patients and mortality in $2.7 \%$. Ninety percent of patients had a good clinical outcome. Aneurysm size (OR 1.4, 95\% Cl 1.08-1.7; $p=0.009)$ and location in the posterior circulation were significantly associated with higher complications. All 3 patients who had coil extraction experienced a postoperative stroke. Aneurysm size (OR 1.2, 95\% Cl 1.02-1.45; $p=0.025)$ and higher number of interventions prior to clipping $(O R 5.3,95 \% \mathrm{Cl}$ $1.3-21.4 ; p=0.019$ ) were significant predictors of poor outcome. An aneurysm size $>7 \mathrm{~mm}$ was a significant predictor of incomplete obliteration and retreatment $(p=0.018)$.

CONCLUSIONS Surgical clipping is safe and effective in treating recurrent, previously coiled cerebral aneurysms. Aneurysm size, location, and number of previous coiling procedures are important factors to consider in the management of these aneurysms.

http://thejns.org/doi/abs/10.3171/2015.10.JNS151544

KEY WORDS aneurysm; clipping; previously coiled; recurrence; vascular disorders

$\mathrm{W}$ ITH the tremendous advancements in endovascular therapy, cerebral aneurysms are being managed more commonly using endovascular techniques. The successful short-term outcomes of coiling are well established, with significantly reduced morbidity and mortality compared with the more invasive surgical clipping. ${ }^{13,14}$ However, with the increasing number of cases treated with coiling and longer duration of followup, the long-term outcomes and drawbacks have evolved, including but not limited to high number of recurrences, incomplete obliteration, rebleeding, and coil compaction and extrusion..$^{2,7,10}$

Treatment of recurrent aneurysms can be challenging. Although definitive guidelines have not been established, these aneurysms are widely treated using different surgical and endovascular techniques. The main surgical treatment options include direct microsurgical clipping, extracranial-intracranial bypass with parent vessel occlusion, or aneurysm wrapping ${ }^{4,6,8}$ Endovascular treatment strategies include recoiling, stenting, stent-assisted coil emboliza-

ABBREVIATIONS ACoA = anterior communicating artery; $m R S=$ modified Rankin Scale; PCoA = posterior communicating artery; PED = Pipeline Embolization Device. SUBMITTED July 2, 2015. ACCEPTED October 22, 2015.

INCLUDE WHEN CITING Published online February 19, 2016; DOI: 10.3171/2015.10.JNS151544. 
tion, or the use of flow-diversion devices such as the Pipeline Embolization Device (PED) ${ }^{18,19}$ Although retreatment with recoiling is effective in some patients, up to $50 \%$ of cases may still require further treatment. ${ }^{18}$

Surgical clipping has been shown to effectively treat intracranial aneurysms with higher rates of complete obliteration compared with endovascular coiling. ${ }^{2}$ However, clipping of previously coiled aneurysms can be challenging; it has its own limitations and technical difficulties attributed to the previously placed coils. The literature on clipping of previously coiled intracranial aneurysms is still limited, with few institutions reporting their initial experiences. ${ }^{1,15,21,27}$ With the growing population of patients harboring recurrent aneurysms, the need for retreatment is growing. More studies are required to evaluate the strategies that should be implemented in the management of recurrent aneurysms. The objective of this study was to evaluate the efficacy and safety of microsurgical clipping in the treatment of recurrent, previously coiled cerebral aneurysms and to identify individual and technical factors that can affect outcomes of this procedure.

\section{Methods \\ Patient Selection}

The study protocol was approved by Thomas Jefferson University's institutional review board. All patients who underwent surgical clipping for the treatment of cerebral aneurysms between January 2002 and October 2014 were reviewed. The inclusion criteria for this retrospective cohort study consisted of patients with prior successful coiling who presented with aneurysm recurrence and who were managed with surgical clipping. Patients with initially attempted but unsuccessful coiling procedures and patients who underwent any endovascular treatment other than coiling prior to surgical clipping (e.g., stent placement, flow diversion) were excluded from the study. One hundred eleven patients who met the study criteria were identified. The total number of aneurysms treated with clipping during the same time period was 933, of which 553 were unruptured and 380 were ruptured aneurysms. The total number of aneurysms managed with coiling was 2632, of which 699 were ruptured and 1933 were unruptured aneurysms.

\section{Variables and Outcomes}

Electronic medical records were reviewed to determine baseline patient, aneurysm, and treatment characteristics; follow-up images and angiograms were reviewed for all patients. Variables including age, sex, smoking status, hypertension, aneurysm rupture and presentation with subarachnoid hemorrhage at the time of initial coiling, aneurysm location, aneurysm size, aneurysm shape, indication for clipping, number of coiling procedures prior to clipping, percent recurrence based on follow-up angiograms postcoiling, time interval from coiling to clipping, angiographic outcomes postclipping, and follow-up duration were recorded for each patient.

The outcomes of interest in this study included the following: 1) the success of the procedure, as measured by the rates of aneurysm occlusion, recurrence on angiographic follow-up, and retreatment after clipping; and 2) the safety of the procedure, as determined by the rate of complications and the rate of favorable versus unfavorable clinical outcomes after the procedure. Clinical outcome was determined by using the modified Rankin Scale (mRS), with an mRS score of 0-2 considered as a favorable or good outcome and an mRS score of 3-6 considered as an unfavorable or bad outcome. The $\mathrm{mRS}$ scores were determined by specialized neurosurgeons based on the last follow-up visit. Complications were diagnosed clinically with new deficits or change in the level of consciousness, or on CT scans or MRI.

\section{Surgical Clipping}

All procedures were performed by neurosurgeons trained in both microsurgical and endovascular procedures. The decision to treat recurrent, previously coiled cerebral aneurysms with microsurgical clipping depended on patient and aneurysm characteristics. In general, aneurysms in certain anatomical locations (mostly in the anterior communicating artery $[\mathrm{ACoA}]$, the middle cerebral artery, and the posterior communicating artery [PCoA]), with wide necks, an unfavorable neck-to-dome ratio, and less densely packed with coils, leaving enough space for clip placement at the neck, were more likely to be clipped. Older patients with multiple comorbidities, posterior circulation aneurysms, and coils densely packed in the aneurysm neck were less likely to be treated with surgical clipping.

The procedures were performed under general endotracheal anesthesia with administration of corticosteroids and diuretics. Continuous neurophysiological monitoring was performed in all patients. Different approaches were followed, depending on the location of the aneurysm. After clipping of the aneurysm, micro-Doppler recordings were checked for patency of the afferent and efferent vasculature and for any ultrasonic evidence of residual flow within the aneurysm. All patients had an intraoperative angiogram to document aneurysm occlusion, patency of the parent vessel, and appropriate positioning of the clip (Figs. 1 and 2).

\section{Statistical Analysis}

Data are presented as mean and range for continuous variables, and as frequency for categorical variables. Analysis was performed using unpaired t-test, chi-square, and Fisher's exact tests, as appropriate. Univariate analysis was used to test covariates predictive of the following dependent variables: complication following clipping, incomplete occlusion and retreatment after clipping, and functional outcome (mRS score of 0-2 vs 3-6). Interaction and confounding were assessed through stratification and relevant expansion covariates. Factors predictive in univariate analysis $(p<0.15)$ were entered into a multivariate logistic regression analysis, and $\mathrm{p}$ values $\leq 0.05$ were considered statistically significant. Statistical analysis was performed using Stata 10.0 (StataCorp).

\section{Results}

\section{Baseline Characteristics}

The mean patient age was $50.5 \pm 11$ years; $74 \%$ were 


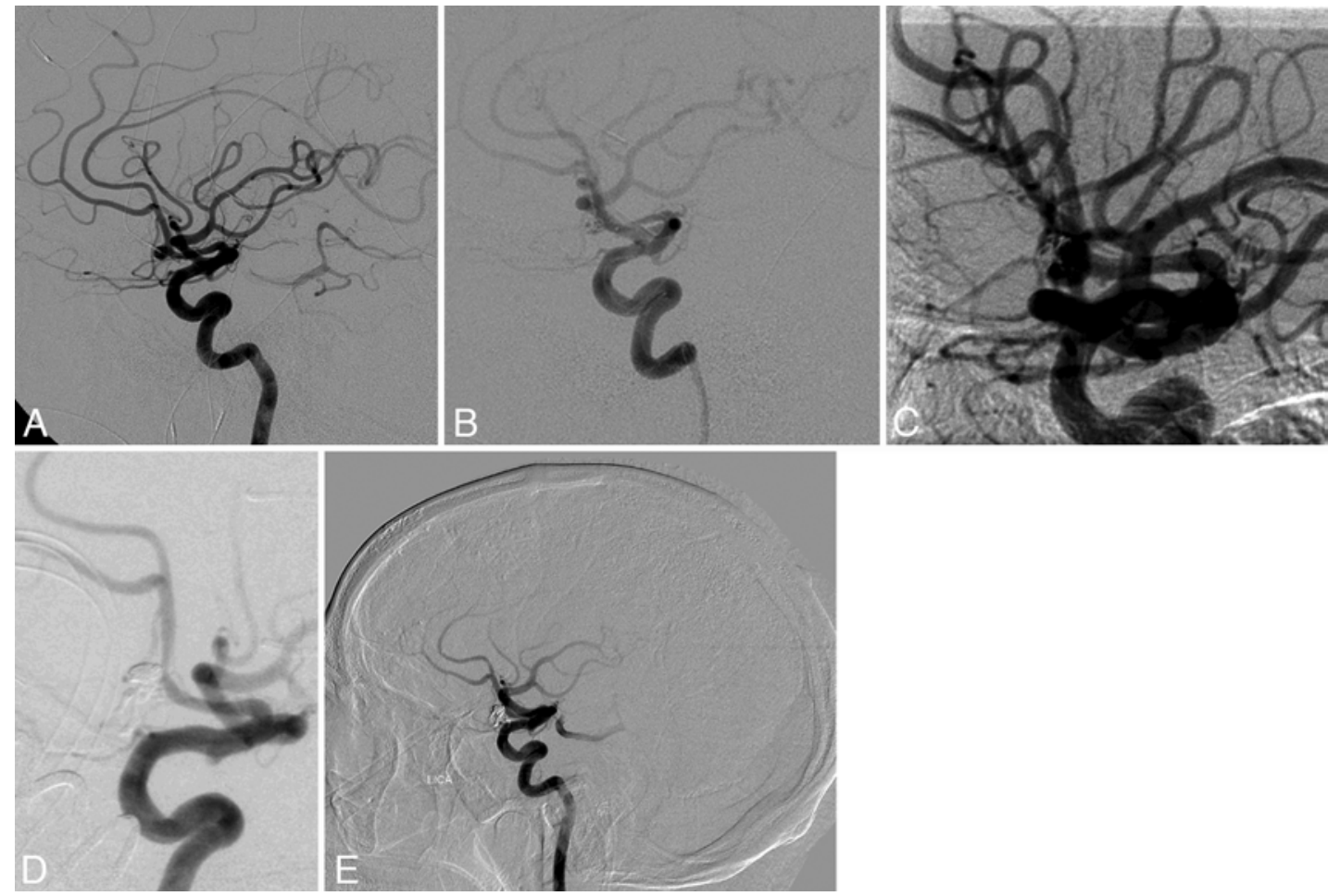

FIG. 1. A: Angiogram obtained in a 41-year-old woman who presented with Grade III subarachnoid hemorrhage secondary to a ruptured 5- $\times$ 4-mm left ACoA aneurysm. B: Coil embolization was performed. The percentage volumetric occupation by coils was $26 \%$. At the completion of the procedure, there was incomplete occlusion of the aneurysm with some filling of the interstices. C: A 1-year follow-up angiogram showed recanalization of the aneurysm. D: A left frontotemporoparietal approach was used for clipping of the left recurrent $A_{2}$ aneurysm. There were no complications. Intraoperative angiogram showed complete obliteration of the aneurysm. E: A 5-year follow-up angiogram showed complete occlusion as well. LICA = left internal carotid artery.

women and $26 \%$ were men. Fifty-nine percent of patients were smokers, and $54 \%$ had a history of hypertension. Seventy-nine percent of patients presented with subarachnoid hemorrhage at the time of initial coiling. One hundred eight aneurysms (97.3\%) were located in the anterior circulation, and 3 aneurysms (2.7\%) were located in the vertebrobasilar circulation. Aneurysm locations are detailed in Table 1.

The mean aneurysm size was $7 \pm 3 \mathrm{~mm} ; 54 \%$ of aneurysms were $<7 \mathrm{~mm}, 36.5 \%$ were $7-12 \mathrm{~mm}, 8.2 \%$ were 13 $24 \mathrm{~mm}$, and $1.1 \%$ were $\geq 25 \mathrm{~mm}$. Most aneurysms were saccular (97.3\%). The mean percent recurrence, based on follow-up angiogram after coiling, was $40 \% \pm 25 \%$. The mean follow-up duration was 22 months after the clipping procedure. Ninety-three patients $(84 \%)$ had 1 coiling intervention prior to clipping, 17 patients $(15 \%)$ had 2 coiling procedures prior to clipping, and 1 patient (1\%) had 3 prior coiling interventions. The mean time interval from coiling to clipping was 23 months.

\section{Surgical Clipping}

The indications for microsurgical clipping after coiling included aneurysm recanalization in 95 of 111 patients $(85.6 \%)$ and aneurysm residual in 16 of 111 patients (14.4\%). Coil compaction was observed in 19 patients (17\%) on follow-up angiogram and was confirmed intraoperatively. The clinical indications for the procedure included rebleeding after coiling in 2 patients (1.8\%), headaches in
7 patients $(6.3 \%)$, third cranial nerve palsy in 4 patients (3.6\%), and 1 patient $(0.9 \%)$ presented with symptoms of dysphagia and dysarthria. An angiogram was obtained in these patients and showed recurrence or residual lesion. Aneurysm recurrence or residual was documented incidentally on follow-up angiograms in the remaining $87.4 \%$ of patients. Intraoperative aneurysm rupture did not occur in any of the patients. Coil extraction was performed in 3 patients (2.7\%), all of whom suffered a postoperative stroke. Temporary clips were used in 40 patients (36\%) to allow slackening and mobilization of the aneurysm complex. Direct aneurysm clipping was technically challenging in 6 patients (5.4\%), with failed clipping attempts. Aneurysm wrapping was performed in these patients.

\section{Clinical Outcomes}

Complete aneurysm occlusion, as assessed by intraoperative angiography, was achieved in $97.3 \%$ of aneurysms after surgical intervention (108 of 111 patients) (Fig. 3). Two patients $(1.8 \%)$ had a recurrence after clipping during follow-up. Another intervention was performed in those patients who had an unsuccessful clipping procedure or recurrence of the aneurysm after surgical management. In total, 5 of 111 patients $(4.5 \%)$ required retreatment to achieve complete occlusion after clipping. Major postoperative complications with resultant neurological morbidity occurred in $8 \%$ of patients. All postoperative complications (including stroke, intracerebral hemorrhage, 


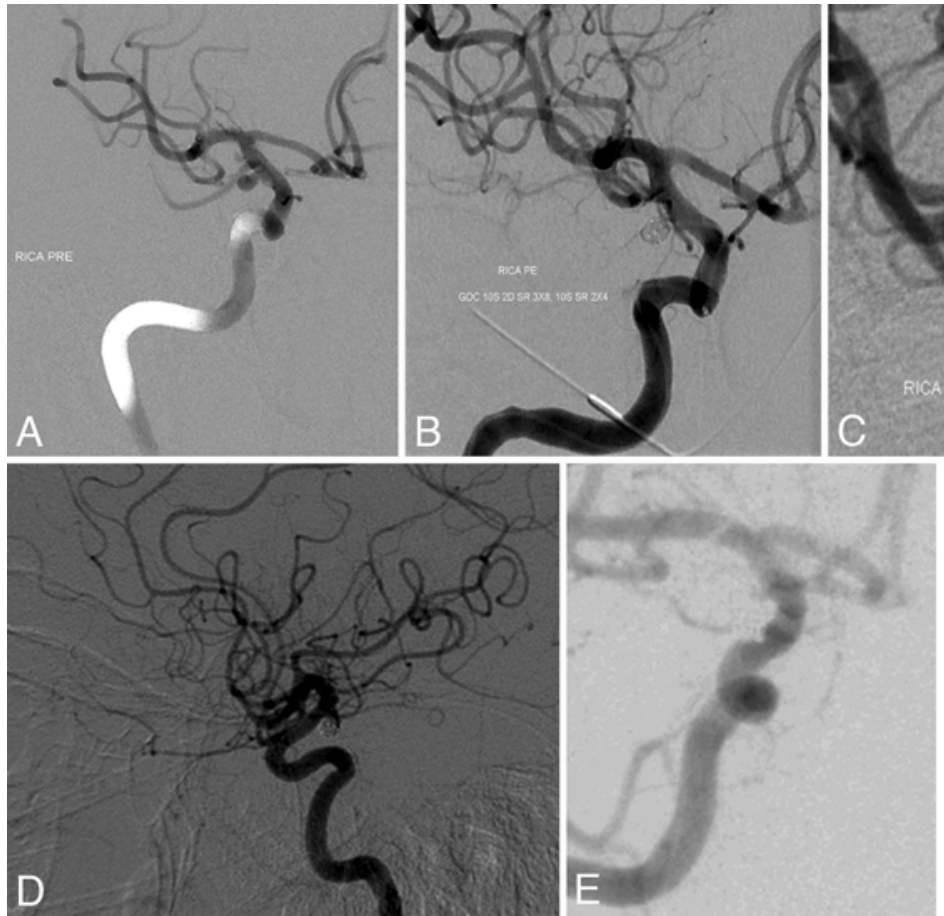

FIG. 2. A: Angiogram obtained in a 46-year-old woman who had a sentinel headache secondary to a right 3.5- $\times 4.5-\mathrm{mm} P C o A$ aneurysm. B: Endovascular coiling was performed to treat the aneurysm. The percentage volumetric occupation by coils was $29 \%$. At the completion of the procedure, complete occlusion of the aneurysm was achieved. C: A 6-month follow-up angiogram showed complete occlusion as well. D: At 15 months postcoiling, the patient presented with headache. An angiogram was obtained, showing recurrence of the PCoA aneurysm. E: The patient underwent a right-sided craniotomy for clip ligation of the aneurysm. An intraoperative angiogram showed complete occlusion of the aneurysm. There were no complications. GDC $=\mathrm{Gug}$ lielmi detachable coil; PE and PRE = before clip placement; RICA = right internal carotid artery.

hydrocephalus, infection, subdural hematoma, and seizures) were observed in 17 patients (15\%). Mortality was observed in 3 of 111 patients $(2.7 \%)$. Postoperative complications are detailed in Table 2 . Ninety percent of patients had a good outcome at their last follow-up visit, with an mRS score of $0-2$ (Table 3).

\section{Predictors of Outcomes}

A statistical analysis was conducted for further characterization of aneurysms that had a negative clinical or radiographic outcome. In multivariate analysis, factors that were significantly associated with the occurrence of complications included aneurysm size (OR 1.4, 95\% CI

TABLE 1. Aneurysm locations among 111 patients

\begin{tabular}{lcc}
\hline \multicolumn{1}{c}{ Location } & No. & $\%$ \\
\hline ACoA & 55 & 49.5 \\
\hline PCoA & 29 & 26.1 \\
\hline MCA & 9 & 8.1 \\
\hline Pericallosal & 7 & 6.3 \\
\hline Carotid ophthalmic & 3 & 2.7 \\
\hline Vertebrobasilar & 3 & 2.7 \\
\hline ICA terminus & 3 & 2.7 \\
\hline Anterior choroidal & 1 & 0.9 \\
\hline Superior hypophyseal & 1 & 0.9 \\
\hline
\end{tabular}

$\mathrm{ICA}=$ internal carotid artery; $\mathrm{MCA}=$ middle cerebral artery.
$1.08-1.7 ; p=0.009$ ) and location, with aneurysms located in the vertebrobasilar circulation resulting in the highest rate of complications compared with other locations (OR 9.3, 95\% CI 1.1-74.5; $p=0.036$ ). Furthermore, in univariate analysis, aneurysm size $>7 \mathrm{~mm}$ was significantly associated with higher odds of complications (OR 22.4, $95 \%$ CI 2.6-190.5; $\mathrm{p}=0.004)$. In both uni- and multivariate analysis, larger aneurysm size (OR 1.2, 95\% CI 1.02-1.45; $\mathrm{p}=0.025)$ and higher number of interventions prior to clipping (OR 5.3, 95\% CI 1.3-21.4; $\mathrm{p}=0.019$ ) were significant predictors of poor outcome. In univariate analysis, aneurysm size $>7 \mathrm{~mm}$ (OR 4.9, 95\% CI 1.13-21.3; p $=0.034)$ and having perioperative complications (OR 16, 95\% CI 3.9-62.6; $\mathrm{p}<0.001$ ) carried higher odds of poor clinical outcome. In both uni- and multivariate analyses, the only significant predictor of aneurysm recurrence and retreatment was size $>7 \mathrm{~mm}(\mathrm{p}=0.018)$. Furthermore, all retreatments occurred in aneurysms $>7 \mathrm{~mm}$.

\section{Discussion}

Endovascular coiling has become the standard of treatment for a large proportion of cerebral aneurysms. Although less invasive than surgical clipping, aneurysm coiling presents with higher recurrence rates, which necessitates more retreatments to reduce the risk of future hemorrhage. ${ }^{2}$ Approximately $20 \%$ of all coiled cerebral aneurysms recur, and $10 \%$ of coiled aneurysms require another intervention. ${ }^{5}$ With the growing population of re- 

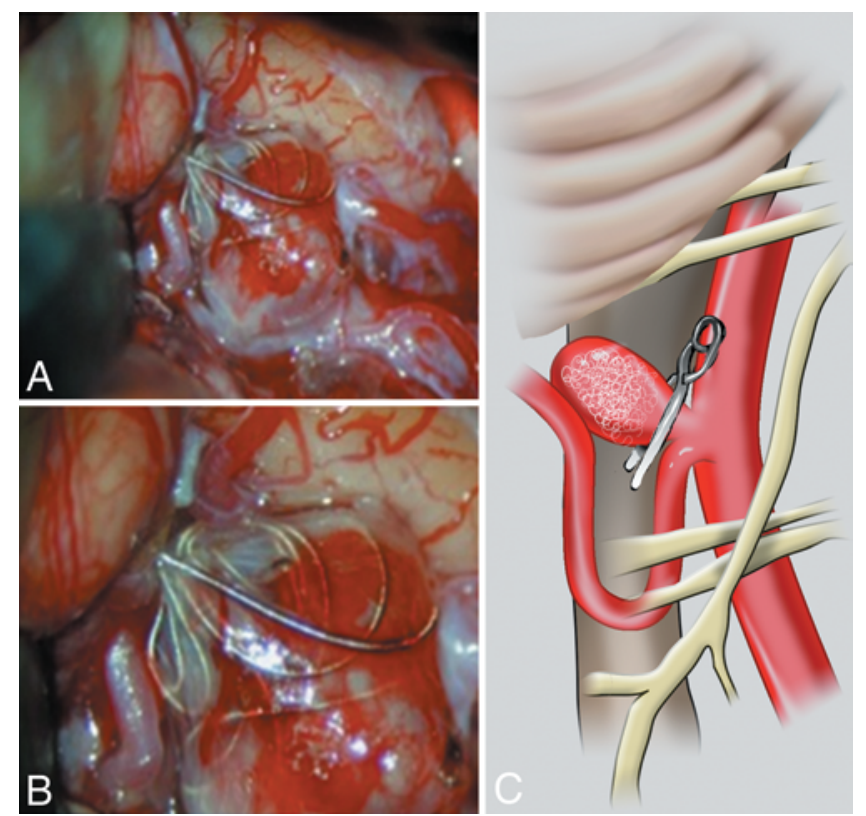

B

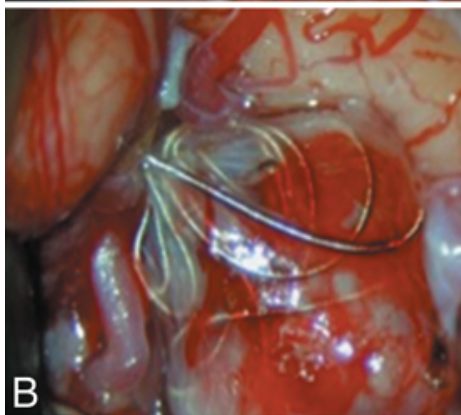

FIG. 3. A and B: Intraoperative images of clipping of a previously coiled aneurysm. C: An illustration of clipping of a previously coiled aneurysm. Copyright Pascal Jabbour. Published with permission.

current, previously coiled cerebral aneurysms, treatment strategies have to be implemented to address this issue. This study represents the largest single-center experience to date highlighting the use of surgical clipping in the management of recurrent, previously coiled cerebral aneurysms. A high success rate, high rate of good clinical outcome, low retreatment rate, and low rate of complications were observed in this cohort of 111 patients.

Clipping of coiled aneurysms is more technically challenging than surgical clipping of untreated aneurysms. However, with appropriate patient selection, the efficacy of the procedure is high and complications are minimal. For this reason, a multidisciplinary approach is required to guide patient selection for the retreatment procedure. The aneurysms that were retreated with clipping had a significant recurrence after coiling (mean $40 \%$ ) and/or were progressing on follow-up, and had a favorable morphology, with a wide neck and no coil loops in the neck, as evaluated on angiography prior to clip placement.

Microsurgical clipping of coiled aneurysms is best accomplished by direct clipping of the aneurysm neck. The feasibility of this procedure depends on several factors, including the time interval between the coiling procedure and microsurgical clipping, the position of the coils within

TABLE 2. Complications among 111 patients who underwent clipping of previously coiled cerebral aneurysms

\begin{tabular}{lcc}
\hline \multicolumn{1}{c}{ Complication } & No. & $\%$ \\
\hline Ischemic stroke & 8 & 7.2 \\
\hline Subdural hematoma & 1 & 0.9 \\
\hline Seizures & 4 & 3.6 \\
\hline Infection & 3 & 2.7 \\
\hline Hydrocephalus & 1 & 0.9 \\
\hline
\end{tabular}

TABLE 3. Clinical outcomes among 111 patients who underwent clipping of previously coiled cerebral aneurysms

\begin{tabular}{ccc}
\hline Clinical Outcome (mRS score) & No. & $\%$ \\
\hline 0 & 50 & 45 \\
\hline 1 & 31 & 27.9 \\
\hline 2 & 19 & 17.1 \\
\hline 3 & 4 & 3.6 \\
\hline 4 & 4 & 3.6 \\
\hline 5 & 0 & 0 \\
\hline 6 & 3 & 2.7 \\
\hline
\end{tabular}

the aneurysm, and the space available at the base of the aneurysm for clip placement. ${ }^{1,21,27}$ Technical difficulties attributed to the coils present in the aneurysmal sac and neck are frequently encountered, making it difficult to properly clip the aneurysm and sometimes requiring removal of such coils. ${ }^{9,11,25}$

The removal of coils for clip placement carries high morbidity. Each of the 3 patients who had coil extraction suffered a stroke postoperatively. When direct clipping is not possible, with coil loops extending into the aneurysm neck, or with significant transmural calcification and scarring, other techniques should be considered. Wrapping of the aneurysm was attempted in these difficult cases and was successful in all patients, with good outcomes. Other techniques reported in the literature include extracranialintracranial bypass and trapping or proximal vessel occlusion. ${ }^{1,21}$

The high rate $(97.3 \%)$ of complete obliteration in this study is consistent with previous reports in the literature. In a retrospective study that included 82 previously coiled aneurysms, Romani et al. reported a similar rate (94\%) of complete occlusion after surgical clipping. ${ }^{21}$ Waldron et al. reported that 32 of 33 (97\%) previously coiled aneurysms were completely occluded without residual filling after microsurgical clipping. ${ }^{27}$ Other smaller studies reported

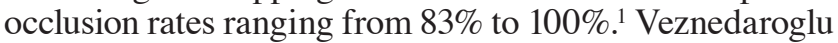
et al. reported that the presence of coils in the aneurysm dome and/or neck makes clipping and exposure of the aneurysm neck difficult, leading to an increased risk of incomplete obliteration ( 3 of 18 patients in their study). ${ }^{26}$ Although previous coil placement can cause significant scarring and change in the aneurysm morphology, in our experience, direct clipping of the coiled aneurysm neck can be accomplished successfully in most patients.

Major complications were observed in $8 \%$ of patients. Romani et al. reported complications leading to major morbidity and mortality in 10 of 81 patients $(12 \%){ }^{21}$ Zhang et al. reported complications in 7 of 38 patients $(18 \%)^{29}$ Waldron et al. reported that the rate of surgical mortality was $7 \%$, the permanent neurological morbidity rate was $2 \%$, and the remaining 39 patients $(91 \%)$ had good outcomes. ${ }^{27}$ The International Subarachnoid Aneurysm Trial reported that 22 patients had neurosurgical treatment after initial coiling. The investigators did not observe any complications in these patients, and only 2 patients had a worsened outcome (mRS score $>2) .^{2}$ Similarly, in the present study, $90 \%$ of patients had a good clinical outcome during 
follow-up. The morbidity and mortality rates observed in this study and several other studies are comparable to the ones recorded with the surgical clipping of uncoiled aneurysms, among patients undergoing clipping as a first-line treatment. In a meta-analysis of 2460 patients, Raaymakers et al. reported a rate of permanent morbidity of $10.9 \%$ and a mortality rate of $2.6 \% .^{17}$ This low complication rate is attributed to the low rate of coil extraction, which poses a risk of tearing the aneurysm neck or injuring adjacent structures and carries the highest risks of morbidity and mortality.

Aneurysm size and location play important roles in the patient selection for aneurysm management. Larger aneurysms, mainly $>7 \mathrm{~mm}$, and aneurysms located in the posterior circulation had higher odds of poor outcomes. Aneurysm size and location were reported to be significant predictors of poor outcome after open surgery in the International Study of Unruptured Intracranial Aneurysms study. ${ }^{28}$ These risk factors are further extended to clipping of previously coiled aneurysms. Similarly, Romani et al. found that larger coiled aneurysms and aneurysms in the posterior circulation had worse outcomes after microsurgical clipping. ${ }^{21}$

There are several endovascular treatments that can be used in the management of recurrent, previously coiled aneurysms. The major options include recoiling, stenting, stent-assisted coiling, and flow diversion. Renowden et al. reported an $11 \%$ recurrence after recoiling of previously coiled aneurysms. ${ }^{19}$ Sedat et al. observed that recoiling achieved complete occlusion in $56.8 \%$ of aneurysms.22 Raymond and Darsaut reported that after long-term follow-up, $50 \%$ of aneurysms had recurrences when recoiling was attempted..$^{18}$ The recurrence rates observed with recoiling of recurrent aneurysms exceed the rates reported with surgical clipping. Recurrences of aneurysms with wide necks and unfavorable neck-to-dome ratios would be better candidates for surgical clipping than recoiling.

Furthermore, in many cases, several interventions are required to achieve aneurysm occlusion with coiling. Slob et al. reported that $19.5 \%$ of previously coiled aneurysms required multiple coil treatments to achieve complete or near-complete aneurysm occlusion, with some patients requiring up to 4 coiling procedures. ${ }^{23}$ Ringer et al. reported that $13.2 \%$ of patients required several coiling procedures for successful aneurysm treatment. ${ }^{20}$ In our study, 18 of 111 patients (16.2\%) underwent more than 1 attempt at coiling before microsurgical clipping was performed. Our results show that aneurysms that were managed several times with coiling were more likely to have worse outcomes after the clipping procedure. This can be attributed to the increased amount of scarring and unfavorable aneurysm geometry, both of which can make the clipping procedure more difficult.

Stenting represents another treatment strategy for recurrent aneurysms. Tähtinen et al. reported complete occlusion in $59 \%$ of patients after stent-assisted coiling of recurrent aneurysms, with a complication rate of $11 \% .{ }^{24}$ Compared with our results, microsurgical clipping resulted in a higher occlusion rate with a similar complication rate. Chalouhi et al. observed that prior coil treatment was a predictor of recanalization after stent-assisted coiling. ${ }^{3}$
O'Kelly et al. reported successful occlusion in $83 \%$ of patients after treatment with the PED. ${ }^{16}$ They reported, however, that in patients with previously treated aneurysms, the PED achieved lower occlusion rates. McAuliffe et al. reported that in patients who were not previously treated, the aneurysm occlusion rate with the PED was $92.5 \%$. However, in patients who were previously treated, the occlusion rate was $68.7 \% .^{12}$

Retreatment of previously coiled aneurysms can be attained with multiple strategies. However, this process should be individualized based on the remnant anatomy, the neurosurgeon's expertise, and the efficacy and safety of each technique in the management of recurrent aneurysms. To evaluate candidates for microsurgical treatment, several factors should be considered, including patient's age, comorbidities, and preference to undergo surgical or endovascular intervention. Patients who present with recurrent bleeding from a ruptured aneurysm should be seriously considered to undergo clipping of the recurrent aneurysm. Recurrent aneurysms with a significant recurrence after coiling $(\geq 40 \%)$, aneurysms with recurrence at the neck leaving room for clip application, aneurysms with a wide neck, a neck-to-dome ratio of more than 2:1, aneurysms with a low volumetric occupation by coils, and anterior circulation aneurysms should be seriously considered for surgical management following the first failed coiling intervention.

The major limitations of this study include the fact that the study population was gathered from a single center, which may not always reflect the findings and practices of other institutions; the retrospective nature of the study; and the lack of a control group.

\section{Conclusions}

Surgical clipping is an appropriate treatment strategy for the management of recurrent cerebral aneurysms after endovascular coiling. Direct clipping of the aneurysm neck is feasible in most cases of recurrent, previously coiled cerebral aneurysms. Coil extraction should not be attempted regularly because it is associated with high morbidity. Aneurysm size, location, and number of prior interventions are important factors that can affect the safety and efficacy of clipping in the management of recurrent, previously coiled aneurysms. With the growing number of recurrent and residual aneurysms after endovascular treatment, more comparative studies between the different surgical and endovascular approaches are required to establish the best treatment to manage these aneurysms.

\section{References}

1. Arnaout OM, El Ahmadieh TY, Zammar SG, El Tecle NE, Hamade YJ, Aoun RJ, et al: Microsurgical treatment of previously coiled intracranial aneurysms: systematic review of the literature. World Neurosurg 84:246-253, 2015

2. Campi A, Ramzi N, Molyneux AJ, Summers PE, Kerr RS, Sneade M, et al: Retreatment of ruptured cerebral aneurysms in patients randomized by coiling or clipping in the International Subarachnoid Aneurysm Trial (ISAT). Stroke 38:1538-1544, 2007

3. Chalouhi N, Jabbour P, Singhal S, Drueding R, Starke RM, Dalyai RT, et al: Stent-assisted coiling of intracranial aneu- 
rysms: predictors of complications, recanalization, and outcome in 508 cases. Stroke 44:1348-1353, 2013

4. Chung J, Lim YC, Kim BS, Lee D, Lee KS, Shin YS: Early and late microsurgical clipping for initially coiled intracranial aneurysms. Neuroradiology 52:1143-1151, 2010

5. Ferns SP, Sprengers ME, van Rooij WJ, Rinkel GJ, van Rijn JC, Bipat S, et al: Coiling of intracranial aneurysms: a systematic review on initial occlusion and reopening and retreatment rates. Stroke 40:e523-e529, 2009

6. Izumo T, Matsuo T, Morofuji Y, Hiu T, Horie N, Hayashi K, et al: Microsurgical clipping for recurrent aneurysms after initial endovascular coil embolization. World Neurosurg 83:211-218, 2015

7. Johnston SC, Dowd CF, Higashida RT, Lawton MT, Duckwiler GR, Gress DR : Predictors of rehemorrhage after treatment of ruptured intracranial aneurysms: the Cerebral Aneurysm Rerupture After Treatment (CARAT) study. Stroke 39:120-125, 2008

8. Kato Y, Kumar A, Chen S: Surgical nuances of clipping after coiling: looking beyond the international subarachnoid aneurysm trial. J Clin Neurosci 19:638-642, 2012

9. Klein O, Colnat-Coulbois S, Civit T, Auque J, Bracard S, Pinelli C, et al: Aneurysm clipping after endovascular treatment with coils: a report of 13 cases. Neurosurg Rev 31:403-411, 2008

10. Kole MK, Pelz DM, Kalapos P, Lee DH, Gulka IB, Lownie SP: Endovascular coil embolization of intracranial aneurysms: important factors related to rates and outcomes of incomplete occlusion. J Neurosurg 102:607-615, 2005

11. Lejeune JP, Thines L, Taschner C, Bourgeois P, Henon H, Leclerc X: Neurosurgical treatment for aneurysm remnants or recurrences after coil occlusion. Neurosurgery 63:684692,2008

12. McAuliffe W, Wycoco V, Rice H, Phatouros C, Singh TJ, Wenderoth J: Immediate and midterm results following treatment of unruptured intracranial aneurysms with the pipeline embolization device. AJNR Am J Neuroradiol 33:164-170, 2012

13. Molyneux A, Kerr R, Stratton I, Sandercock P, Clarke M, Shrimpton J, et al: International Subarachnoid Aneurysm Trial (ISAT) of neurosurgical clipping versus endovascular coiling in 2143 patients with ruptured intracranial aneurysms: a randomised trial. Lancet 360:1267-1274, 2002

14. Molyneux AJ, Kerr RS, Yu LM, Clarke M, Sneade M, Yarnold JA, et al: International subarachnoid aneurysm trial (ISAT) of neurosurgical clipping versus endovascular coiling in 2143 patients with ruptured intracranial aneurysms: a randomised comparison of effects on survival, dependency, seizures, rebleeding, subgroups, and aneurysm occlusion. Lancet 366:809-817, 2005

15. Nakamura M, Montibeller GR, Götz F, Krauss JK: Microsurgical clipping of previously coiled intracranial aneurysms. Clin Neurol Neurosurg 115:1343-1349, 2013

16. O'Kelly CJ, Spears J, Chow M, Wong J, Boulton M, Weill A, et al: Canadian experience with the pipeline embolization device for repair of unruptured intracranial aneurysms. AJNR Am J Neuroradiol 34:381-387, 2013

17. Raaymakers TW, Rinkel GJ, Limburg M, Algra A: Mortality and morbidity of surgery for unruptured intracranial aneurysms: a meta-analysis. Stroke 29:1531-1538, 1998

18. Raymond J, Darsaut TE: An approach to recurrent aneurysms following endovascular coiling. J Neurointerv Surg 3:314318,2011
19. Renowden SA, Koumellis P, Benes V, Mukonoweshuro W, Molyneux AJ, McConachie NS: Retreatment of previously embolized cerebral aneurysms: the risk of further coil embolization does not negate the advantage of the initial embolization. AJNR Am J Neuroradiol 29:1401-1404, 2008

20. Ringer AJ, Rodriguez-Mercado R, Veznedaroglu E, Levy EI, Hanel RA, Mericle RA, et al: Defining the risk of retreatment for aneurysm recurrence or residual after initial treatment by endovascular coiling: a multicenter study. Neurosurgery 65:311-315, 2009

21. Romani R, Lehto H, Laakso A, Horcajadas A, Kivisaari R, von und zu Fraunberg M, et al: Microsurgery for previously coiled aneurysms: experience with 81 patients. Neurosurgery 68:140-154, 2011

22. Sedat J, Chau Y, Moubarak K, Vargas J, Lonjon M: Endovascular treatment of recurrent coiled aneurysms: assessment of complications and rebleeding during a decade in a single center. Interv Neuroradiol 18:14-19, 2012

23. Slob MJ, Sluzewski M, van Rooij WJ, Roks G, Rinkel GJ: Additional coiling of previously coiled cerebral aneurysms: clinical and angiographic results. AJNR Am J Neuroradiol 25:1373-1376, 2004

24. Tähtinen OI, Manninen HI, Vanninen RL, Rautio R, Haapanen A, Seppänen J, et al: Stent-assisted embolization of recurrent or residual intracranial aneurysms. Neuroradiology 55:1221-1231, 2013

25. Thornton J, Dovey Z, Alazzaz A, Misra M, Aletich VA, Debrun GM, et al: Surgery following endovascular coiling of intracranial aneurysms. Surg Neurol 54:352-360, 2000

26. Veznedaroglu E, Benitez RP, Rosenwasser RH: Surgically treated aneurysms previously coiled: lessons learned. Neurosurgery 54:300-305, 2004

27. Waldron JS, Halbach VV, Lawton MT: Microsurgical management of incompletely coiled and recurrent aneurysms: trends, techniques, and observations on coil extrusion. Neurosurgery 64 (5 Suppl 2):301-317, 2009

28. Wiebers DO, Whisnant JP, Huston J III, Meissner I, Brown RD Jr, Piepgras DG, et al: Unruptured intracranial aneurysms: natural history, clinical outcome, and risks of surgical and endovascular treatment. Lancet 362:103-110, 2003

29. Zhang YJ, Barrow DL, Cawley CM, Dion JE: Neurosurgical management of intracranial aneurysms previously treated with endovascular therapy. Neurosurgery 52:283-295, 2003

\section{Disclosures}

Dr. Tjoumakaris is a consultant for Stryker and Covidien.

\section{Author Contributions}

Conception and design: Jabbour, Daou, Tjoumakaris, Rosenwasser. Acquisition of data: Daou, Starke, Barros, Ya'qoub, Do. Analysis and interpretation of data: all authors. Drafting the article: Jabbour, Daou, Chalouhi. Critically revising the article: Jabbour, Daou, Chalouhi, Tjoumakaris, Rosenwasser. Reviewed submitted version of manuscript: all authors. Approved the final version of the manuscript on behalf of all authors: Jabbour. Statistical analysis: Starke. Study supervision: Jabbour.

\section{Correspondence}

Pascal M. Jabbour, Department of Neurological Surgery, Thomas Jefferson University Hospital, 901 Walnut St., 3rd Fl., Philadelphia, PA 19107. email: pascal.jabbour@jefferson.edu. 